\title{
EVALUATION OF DENTAL HEALTH EDUCATION IN A SCHOOL DENTAL CARE PROGRAM
}

\author{
David M. Roder, BDS, MPH ${ }^{*}$ \\ Brian A. Burt, BDSc, MPH, PhD ${ }^{\circ \circ}$
}

Dental health educational activities are frequent components of school dental care programs, but their effectiveness has seldom been evaluated. In this report, one method for evaluating these activities is presented and the validity of results discussed in the context of the constraints inherent in the nonexperimental design.

\section{Background to the study}

Dental health education is part of the curriculum in many school systems around the world. ${ }^{1725}$ The rationale is that prevention is the key to controlling dental disease, that caries and periodontal disease are largely preventable through personal behavior, and that the educational environment of the school is the logical place to teach dental health practices which will result in better dental health for today's children and tomorrow's adults. 2,6

The benefits that materialize from these efforts, however, are difficult to substantiate. In their comprehensive review published in 1971, Rayner and Cohen ${ }^{25}$ described the equivocal nature of results from studies to that time. Since that review, some studies have reported improvements in oral hygiene following an educational program, ${ }^{12.20 .21 .30 .33}$ but there appears to be at least as many which show little or no positive results that can be attributed to the educational program. ${ }^{9.11,23,24,32,34}$ Other reported studies are difficult to assess because they did not evaluate health outcomes; "success" was determined by the reactions expressed by students, teachers, or parents. ${ }^{16,19,22,37}$

In a recent appraisal of the effectiveness of dental health educational programs, Frazier ${ }^{10}$ concluded that traditional activities which attempt to motivate individuals to alter their behavior were conceptually faulty, and furthermore were founded upon assumptions that cannot be supported by empirical data. Heifetz and Suomi ${ }^{13}$ were equally unenthusiastic, stating that there was no technology known to be effective at achieving voluntary behavioral change on a community basis. Nevertheless, despite the currently prevalent view that traditional dental health educational programs are ineffective, they continue to be a major part of publicly funded school dental care programs in many countries. ${ }^{15,27,31}$

It seems that uncertainty about the value of these dental health educational programs might be perpetuated by the inherent difficulties in their evaluation. Such evaluation as has been undertaken, as in the studies cited previously, has been mostly short-term, and usually directed at dental health educational programs that were not part of the dental treatment programs. However, some exceptions have been reported. Results from the World Health Organization, Division of Dentistry,

\footnotetext{
-Visiting Assistant Professor of Dental Public

- Associate Professor of Dental Public Health

(Both from the Program in Dental Public Health School of Public Health

The University of Michigan, Ann Arbor, Michigan 48109).

(Submitted 9/19/77; returned for revisions 10/7/77; resubmitted 10/14/77; accepted for publication 11/30/77.)
} 
International Collaborative Study have indicated that gingival health tended to be better among children in countries with long-standing school dental treatment programs. ${ }^{3}$ In addition, a Danish study showed that schoolchildren with a history of school dental care had marginally less gingivitis than children who had not received such care. ${ }^{15}$ Despite the many factors that could account for these findings, it could be hypothesized that constant exposure to dental health education with a school dental treatment program may have some beneficial effect on behavior over time, whereas isolated dental health education programs may have little impact. It is possible that the constant presence of dental treatment personnel, either within the school or in proximity to it, together with regular attendance at the dental facility, imparts more credibility to dental health education among recipients than when it is carried out as a separate program. If so, then the longterm results in school dental treatment situations may be different from those found in experimental studies.

Clearly, the effect of dental health education in a governmental school dental service should be evaluated, for such educational programs can absorb a considerable proportion of the budget. A major barrier to evaluating these efforts, however, is the difficulties in setting up true experimental situations in public programs. Control groups would be required, meaning that randomly chosen children would be denied any potential benefits of the programs being tested. In tax-supported programs, such research is politically difficult to initiate. The evaluation that does take place, therefore, is bound to employ nonexperimental designs ${ }^{4,14,35}$ or what at best could be termed quasi-experimental designs. ${ }^{30}$

The method of evaluation now to be reviewed is based on assessments of oral hygiene status and gingival health in large groups of children by clinical staff of the South Australian School Dental Service.

\section{The School Dental Service}

Detailed descriptions of the structure and process of the South Australian School Dental Service have been given in other reports. ${ }^{8,27-29}$ Briefly, most care is delivered to primary schoolchildren (ages 5-12 years) by dental therapists, who operate in clinical facilities built on the school site. The dental therapists, who began operating in 1969, receive two years of training, and function under the general supervision ${ }^{1}$ of dentists. They undertake both reversible and irreversible procedures. The therapists also are trained to carry out dental inspections at both initial and recall examinations. The initial dental inspections usually are undertaken by therapists, but then are checked by the supervising dentists, who thereafter maintain a periodic surveillance of each child.

Supervising dentists have the responsibility of arranging for follow-up examinations after the initial cycle of care has been completed. Virtually all children enrolled in the program receive complete cycles of care on a periodic basis, normally at nine-month intervals throughout their primary school years. Because children are readily available for care at school, they rarely are lost from the program unless they transfer to a school without a clinic. Children are treated on a classroom basis, or sometimes in alphabetical order, rather than by dental need.

'Not to mention the ethical aspects. See Horowitz's paper in the issue.-Ed. 
Therapists spend approximately $15-20$ percent of their time carrying out traditional dental health education activities in classrooms and at the chairside. No specific goals are set; therapists attempt to influence the oral care behavior of the children through the traditional methods of repeated and direct counseling.

Not all schools as yet have their clinics built, equipped, and staffed. Consequently, two thirds of the State's primary school children still have not been exposed to dental care at school. The state government, acting upon the advice of the program administrator, determines the order in which clinics are established. Major considerations in reaching these decisions are school size, accessibility of alternative dental services, socioeconomic characteristics, and the availability of supervising dentists. In schools where clinics are functioning, over 90 percent of children accept comprehensive dental care in the program; this care excludes specialist orthodontic care and cast-metal restorations.

\section{Evaluation Study Design}

The Service's evaluation unit obtains data on oral conditions from records of the routine clinical examinations undertaken by dentists and therapists. Crosssectional comparisons are made between data for children with different degrees of prior exposure to school dental care. In this context, "degree" does not necessarily denote the amount of past care received. Depending on the individual study, it is interpreted either as the number of cycles of care received, or as the number of years during which there was exposure to the program. "Care" signifies any dental attention, even a simple examination, whereas "cycle of care" refers to an organized series of care procedures aimed at maintaining and restoring dental health, and carried out within a relatively short period of time. A "cycle of care" could be simply an examination, if that was the only attention required.

Any statistical association of superior oral hygiene status and gingival health with the degree of prior exposure to school dental care is construed as justification for some confidence in dental health education, even though statistical associations do not of themselves constitute cause and effect.

Although clinical staff, both dentists and therapists, have recorded oral hygiene status and gingivitis levels at all examinations, not all data have been used for evaluation. It has been the practice of the evaluation unit to obtain copies of records pertaining to arbitrarily chosen time periods only, so as to reduce processing costs. Clinical staff were not told in advance which time periods would be chosen, in order to avoid an experimental effect.

In this evaluation model, data are not collected by calibrated examiners, conventional indexes for oral hygiene status and gingivitis are not used, and there is an absence of control of extraneous independent variables apart from age and sex. On the other hand, sample sizes are large and data collection is inexpensive and easy to administer. This employment of dental health data from general clinical records for evaluation is not unique, having been used in the Danish Child Dental Services for some years. ${ }^{14}$

\section{Data Collection and Analysis}

There were three separate phases of data collection, one for 1969-73, the other two in 1976. These phases are represented diagrammatically in Figure 1. In the 
FIGURE 1

A MODEL FOR EVALUATION OF DENTAL HEALTH EDUCATION IN THE SOUTH AUSTRALIAN SCHOOL DENTAL SERVICE

\begin{tabular}{|c|c|c|c|c|}
\hline $\begin{array}{l}\text { Survey } \\
\text { Phase }\end{array}$ & $\begin{array}{l}\text { Survey } \\
\text { Time } \\
\text { Periods } \\
\end{array}$ & $\begin{array}{l}\text { Children } \\
\text { Surveyed }\end{array}$ & $\begin{array}{c}\text { Character- } \\
\text { istic } \\
\text { Surveyed }\end{array}$ & $\begin{array}{c}\text { Cross-sectional } \\
\text { Comparison } \\
\text { Undertaken } \\
\end{array}$ \\
\hline \multirow[t]{3}{*}{ One } & $1969-70$ & $\begin{array}{l}\text { All children } \\
\text { presenting for } \\
\text { initial care } \\
\text { at } 14 \text { new } \\
\text { school dental } \\
\text { clinics }\end{array}$ & $\begin{array}{l}\text { Oral } \\
\text { hygiene } \\
\text { status }\end{array}$ & $\begin{array}{l}\text { New patients (1969-70) } \\
\quad \text { with } \\
\text { recall patients (1972-73) }\end{array}$ \\
\hline & \multirow[t]{2}{*}{$1972-73$} & \multirow{2}{*}{$\begin{array}{l}\text { Sample of } \\
\text { children pre- } \\
\text { senting for } \\
\text { initial or } \\
\text { follow-up care } \\
\text { at these } 14 \\
\text { school dental } \\
\text { clinics }\end{array}$} & \multirow[t]{2}{*}{$\begin{array}{l}\text { Oral } \\
\text { hygiene } \\
\text { status }\end{array}$} & $\begin{array}{l}\text { New patients (1972-73) } \\
\text { with } \\
\text { recall patients (1972-73) }\end{array}$ \\
\hline & & & & $\begin{array}{cc}\begin{array}{c}\text { Recall patients } \\
\text { of care })^{1} \\
\text { with }\end{array} & \\
\text { recall patients } & (>3 \text { cycles } \\
& \text { of care })^{1}\end{array}$ \\
\hline \multirow[t]{2}{*}{ Two } & \multirow[t]{2}{*}{1976} & \multirow{2}{*}{$\begin{array}{l}\text { First } 19,173 \\
\text { children pre- } \\
\text { senting for } \\
\text { initial or } \\
\text { follow-up care } \\
\text { in the State's } \\
63 \text { school } \\
\text { clinics in } 1976 .\end{array}$} & \multirow[t]{2}{*}{$\begin{array}{l}\text { Oral } \\
\text { hygiene } \\
\text { status }\end{array}$} & $\begin{array}{l}\text { New patients } \\
\text { with } \\
\text { recall patients }\end{array}$ \\
\hline & & & & $\begin{array}{cc}\begin{array}{cc}\text { Recall patients } & (1-3 \text { years } \\
\text { of care })^{2} \\
\text { with }\end{array} & \begin{array}{c}(>3 \text { years } \\
\text { recall patients } \\
\text { of care })^{2}\end{array} \\
\end{array}$ \\
\hline \multirow[t]{2}{*}{ Three } & \multirow[t]{2}{*}{1976} & \multirow{2}{*}{$\begin{array}{l}8,007 \text { children, } \\
\text { representing } \\
\text { every third } \\
\text { child present- } \\
\text { ing for initial } \\
\text { or follow-up } \\
\text { care in the } \\
\text { State's } 63 \\
\text { school clinics } \\
\text { in } 1976\end{array}$} & \multirow[t]{2}{*}{$\begin{array}{l}\text { Absence } \\
\text { of } \\
\text { gingivitis }\end{array}$} & $\begin{array}{l}\text { New patients } \\
\text { with } \\
\text { recall patients }\end{array}$ \\
\hline & & & & $\begin{array}{cc}\begin{array}{c}\text { Recall patients } \\
\text { with }\end{array} & \begin{array}{c}1-3 \text { years } \\
\text { of care })^{2}\end{array} \\
\text { recall patients } & \begin{array}{c}(>3 \text { years } \\
\text { of care })^{2}\end{array}\end{array}$ \\
\hline
\end{tabular}

${ }^{1}$ 'Cycle of care' is an organized series of care procedures aimed at restoring and maintaining dental health

${ }^{2}$ Years of continuous enrollment in the school dental program 
first two phases, only data on oral hygiene status were abstracted, whereas gingivitis assessments were obtained in the third phase. The criteria for these assessments will be described. As a result of rapid growth in the Service, the number of examiners ranged from 17 in 1969 to 140 in 1976.

In the first phase of data collection, the initial examination records were collected for each of the 6,697 children who were enrolled in the School Dental Service, and who in 1969-70 attended the first 14 permanent school dental clinics to be constructed. They comprised the total number who were examined at that time. Three years later, the records of a similar number of children, 6,780 , were selected from the same 14 clinics by a systematic routine following a random start. Approximately 500 records were sampled from each clinic. By the time of the second survey, most children were receiving short cycles of maintenance care and the number of enrolled children had grown considerably, so sampling became necessary. Data from the 1969-70 period then were compared with data from the follow-up survey, and cross-sectional comparisons undertaken between children who had received different numbers of cycles of school dental care. The number of cycles varied because, by the time of the follow-up survey, individual clinics had extended their programs progressively to include more adjacent schools. This extension was made possible by the completion of time-consuming accumulated treatment needs, meaning that increasing numbers of patients were scheduled for maintenance care only.

In the second phase, data on oral hygiene status were collected for children aged six, eight, 10 , and 12 years, who had been presented for care in each of the State's 63 school clinics in existence in 1976. As new dental clinics were being established continually in different schools, the children in these arbitrarily chosen agegroups had been exposed to school dental care for varying periods of time. Because the first clinics were opened in 1969 , some of the older children had been enrolled for seven years, whereas others only had become enrolled for the first time in 1976. Also, population mobility and the progressive completion of accumulated treatment needs brought about a continuing number of new patients. Oral hygiene data were obtained from the first 19,173 examination records in 1976. These records were all those processed at the time of this writing, and represented almost 80 percent of the children aged six, eight, 10 , and 12 years who were enrolled in the School Dental Service. The records were obtained from widely distributed geographic regions, and appear to be representative of the whole population. From these records, comparisons were made between the oral hygiene status of children who had received varying years of exposure to school dental care.

In the third phase of data-collection, also in 1976, gingivitis assessments were obtained for every third child aged six, eight, 10, and 12 years enrolled in the program's 63 clinics. The sample totaled 8,007 children and was analyzed using the same method as for the second phase.

\section{Criteria}

For scoring oral hygiene status in the first phase, operators simply provided subjective ratings of "good" or "poor" guided only by the extent of debris on the teeth. In the second phase, each of six dental-arch segments was examined for the "clearly visible" presence of soft deposits at the gingival margin of one or more 
teeth, without drying the teeth and without the use of disclosing solutions. The criteria and scoring method comply with recommendations of the World Health Organization..$^{36}$ The evaluation unit defined oral hygiene status as "good" if no more than two segments were found to be affected. In the third phase, gingivitis was assessed on a whole-mouth basis as "present" or "absent." Gingivitis was defined as inflammation clearly evident on a close examination, without drying the gingiva. Examinations for both oral hygiene status and the presence or absence of gingivitis were designed for ease and quickness.

When comparing these scores for children with different histories of exposure to school dental care, inferential tests were not employed because it was doubtful whether an assumption of independent sampling elements was appropriate. Furthermore, other weaknesses in research design, such as lack of randomization, seemed too great to justify the application of these tests. Analysis was therefore restricted to an investigation of trends across age-sex specific groups.

\section{Findings}

\section{First Phase: Oral Hygiene Status, 1969-73}

In 15 of the 18 age-sex specific groups, the collective assessments of oral hygiene status for children with a history of dental care in school were superior to the baseline assessments for subjects at their first school dental examination (Tables I and II). These collective assessments also were better than for children in the follow-up survey who were yet to receive dental care at school; a finding which applied to 15 of the 16 age-sex specific groups with adequate numbers for a comparison. Children who had received more than three cycles of dental care in school apparently had better oral hygiene levels than other treated subjects in nine of the 13 age-sex specific groups in the follow-up survey, but this difference does not constitute a convincing trend.

\section{Second Phase: Oral Hygiene Status, 1976}

As shown in Table III, children with histories of dental care in school had better oral hygiene ratings in each age-sex specific group. Moreover, in the six age-sex specific groups with adequate numbers for a comparison, children with the longest histories of dental care in school had cleaner teeth than other treated subjects.

\section{Third Phase: Gingivitis Status, 1976}

From Table IV, it is apparent that children with histories of dental care in school had less gingivitis. However, there is no suggestion that gingival health in treated children improved progressively with the degree of exposure to this care.

\section{Discussion}

\section{Interpretation of Findings}

It may be inferred tentatively from the data in Tables I to IV that a history of school dental care is positively associated with "good" oral hygiene status and an "absence" of gingivitis. Nonetheless, alternative rival explanations for these results must be considered. Without randomization, "blind" examinations, examiner 


\section{TABLE I}

ORAL HYGIENE ASSESSMENTS FOR 5-8-YEAR-OLD CHILDREN IN THE SOUTH AUSTRALIAN SCHOOL DENTAL SERVICE, AS RELATED TO EXPOSURE TO CYCLES OF SCHOOL DENTAL CARE

\begin{tabular}{|c|c|c|c|c|}
\hline Age-Sex & $\begin{array}{l}\text { Time } \\
\text { Period }\end{array}$ & $\begin{array}{c}\text { Treatment Cycles } \\
\text { Received }\end{array}$ & $\begin{array}{l}\text { Number of } \\
\text { Subjects }\end{array}$ & $\begin{array}{c}\text { Percentage with "Good" } † \\
\text { Oral Hygiene }\end{array}$ \\
\hline \multirow[t]{4}{*}{5 yr. M } & $1969-70$ & Baseline & 210 & 74.1 \\
\hline & $1972-73$ & 0 & 350 & 56.9 \\
\hline & & $1-3$ & 63 & 72.6 \\
\hline & & $>3$ & 1 & - \\
\hline \multirow[t]{4}{*}{5 yr. F } & $1969-70$ & Baseline & 183 & 72.2 \\
\hline & $1972-73$ & 0 & 324 & 62.3 \\
\hline & & $1-3$ & 67 & 75.4 \\
\hline & & $>3$ & 1 & - \\
\hline \multirow[t]{4}{*}{6 yr. M } & $1969-70$ & Baseline & 292 & 59.9 \\
\hline & $1972-73$ & 0 & 128 & 60.5 \\
\hline & & $1-3$ & 221 & 59.7 \\
\hline & & $>3$ & 2 & - \\
\hline \multirow[t]{4}{*}{$6 \mathrm{yr} . \mathrm{F}$} & $1969-70$ & Baseline & 266 & 53.0 \\
\hline & $1972-73$ & 0 & 143 & 57.4 \\
\hline & & $1-3$ & 215 & 70.6 \\
\hline & & $>3$ & 1 & - \\
\hline \multirow[t]{4}{*}{7 yr. M } & $1969-70$ & Baseline & 456 & 51.0 \\
\hline & $1972-73$ & 0 & 166 & 46.0 \\
\hline & & $1-3$ & 256 & 52.6 \\
\hline & & $>3$ & 20 & 60.0 \\
\hline \multirow[t]{4}{*}{7 yr. F } & $1969-70$ & Baseline & 424 & 57.6 \\
\hline & $1972-73$ & 0 & 154 & 48.0 \\
\hline & & $1-3$ & 245 & 61.8 \\
\hline & & $>3$ & 24 & 62.5 \\
\hline \multirow[t]{4}{*}{8 yr. M } & $1969-70$ & Baseline & 367 & 49.7 \\
\hline & $1972-73$ & 0 & 122 & 36.7 \\
\hline & & $1-3$ & 269 & 51.5 \\
\hline & & $>3$ & 41 & 67.5 \\
\hline \multirow[t]{4}{*}{8 yr. F } & $1969-70$ & Baseline & 378 & 58.1 \\
\hline & $1972-73$ & 0 & 124 & 41.7 \\
\hline & & $1-3$ & 276 & 54.9 \\
\hline & & $>3$ & 29 & 69.0 \\
\hline
\end{tabular}

-Assessments for one percent of subjects were unavailable because of examiner or recorder omission. Only groups with at least 20 subjects were considered adequate for comparisons.

tSee text for criteria. 
TABLE II

ORAL HYGIENE ASSESSMENTS FOR 9-13-YEAR-OLD CHILDREN IN THE SOUTH AUSTRALIAN SCHOOL DENTAL SERVICE, AS RELATED TO EXPOSURE TO CYCLES OF SCHOOL DENTAL CARE

\begin{tabular}{|c|c|c|c|c|}
\hline Age-Sex & $\begin{array}{l}\text { Time } \\
\text { Period }\end{array}$ & $\begin{array}{c}\text { Treatment Cycles } \\
\text { Received }\end{array}$ & $\begin{array}{l}\text { Number of } \\
\text { Subjects }\end{array}$ & $\begin{array}{c}\text { Percentage with "Good" }+ \\
\text { Oral Hygiene }\end{array}$ \\
\hline \multirow[t]{4}{*}{9 yr. $M$} & $1969-70$ & Baseline & 361 & 48.0 \\
\hline & $1972-73$ & 0 & 83 & 36.3 \\
\hline & & $1-3$ & 305 & 47.8 \\
\hline & & $>3$ & 87 & 58.1 \\
\hline \multirow[t]{4}{*}{9 yr. F } & $1969-70$ & Baseline & 433 & 55.9 \\
\hline & $1972-73$ & 0 & 92 & 44.3 \\
\hline & & $1-3$ & 277 & 61.5 \\
\hline & & $>3$ & 96 & 64.5 \\
\hline \multirow[t]{4}{*}{10 yr. M } & $1969-70$ & Baseline & 555 & 46.5 \\
\hline & $1972-73$ & 0 & 42 & 39.0 \\
\hline & & $1-3$ & 325 & 47.9 \\
\hline & & $>3$ & 98 & 49.5 \\
\hline \multirow[t]{4}{*}{$10 \mathrm{yr} . \mathrm{F}$} & $1969-70$ & Baseline & 521 & 55.7 \\
\hline & $1972-73$ & 0 & 47 & 46.8 \\
\hline & & $1-3$ & 319 & 62.3 \\
\hline & & $>3$ & 107 & 64.4 \\
\hline \multirow[t]{4}{*}{$11 \mathrm{yr} . \mathrm{M}$} & 1969-70 & Baseline & 650 & 46.9 \\
\hline & $1972-73$ & 0 & 36 & 41.2 \\
\hline & & $1-3$ & 349 & 52.5 \\
\hline & & $>3$ & 102 & 53.5 \\
\hline \multirow[t]{4}{*}{$11 \mathrm{yr} . \mathrm{F}$} & 1969-70 & Baseline & 619 & 60.6 \\
\hline & $1972-73$ & 0 & 30 & 50.0 \\
\hline & & $1-3$ & 292 & 72.6 \\
\hline & & $>3$ & 112 & 66.4 \\
\hline \multirow[t]{4}{*}{12 yr. M } & 1969-70 & Baseline & 431 & 46.2 \\
\hline & $1972-73$ & 0 & 34 & 38.7 \\
\hline & & $1-3$ & 210 & 52.2 \\
\hline & & $>3$ & 78 & 52.0 \\
\hline \multirow[t]{4}{*}{12 yr. F } & 1969-70 & Baseline & 381 & 59.4 \\
\hline & $1972-73$ & 0 & 20 & 57.9 \\
\hline & & $1-3$ & 214 & 74.5 \\
\hline & & $>3$ & 68 & 66.2 \\
\hline \multirow[t]{4}{*}{13 yr. M } & $1969-70$ & Baseline & 97 & 35.8 \\
\hline & $1972-73$ & 0 & 5 & - \\
\hline & & $1-3$ & 51 & 48.9 \\
\hline & & $>3$ & 26 & 38.5 \\
\hline
\end{tabular}


TABLE II Continued

\begin{tabular}{lcccc}
\hline 13 yr. F & $1969-70$ & Baseline & 73 & 43.8 \\
& $1972-73$ & 0 & 1 & - \\
& $1-3$ & 21 & 63.2 \\
& $>3$ & 11 & - \\
\hline
\end{tabular}

- Assessments for one percent of subiects were unavailable because of examiner or recorder omission. Only grouns with at least 20 subjects were considered adequate for comparisons.

thee text for criteria.

TABL.E III

ORAI. HYGIENE ASSESSMENTS FOR CHILDREN ENROLLED IN THE SOUTH AUSTRALIAN SCHOOL DENTAL SERVICE IN 1976, AS RELATED TO FXPOSURE TO SCHOOL DENTAL CARE

\begin{tabular}{|c|c|c|c|}
\hline Age Sex & $\begin{array}{l}\text { Years Exposed to } \\
\text { School Dental Care }\end{array}$ & $\begin{array}{l}\text { Number of } \\
\text { Subjects }\end{array}$ & $\begin{array}{c}\text { Percentage with "Good" } \nmid \\
\text { Oral Hygiene }\end{array}$ \\
\hline \multirow[t]{3}{*}{$6 \mathrm{vr} . \mathrm{M}$} & 0 & 1527 & 34.1 \\
\hline & $1-3$ & 1421 & 44.8 \\
\hline & -3 & 9 & - \\
\hline \multirow[t]{3}{*}{$6 \mathrm{vr} \mathrm{F}$} & 0 & 1422 & 387 \\
\hline & 13 & 1422 & 50.7 \\
\hline & -3 & 12 & - \\
\hline \multirow[t]{3}{*}{$S v e . M$} & 0 & 906 & 27.4 \\
\hline & $1-3$ & 1606 & 35.9 \\
\hline & 23 & 201 & 41.3 \\
\hline \multirow[t]{3}{*}{$8 \mathrm{yr} . \mathrm{F}$} & 0 & 876 & 32.6 \\
\hline & 1.3 & 1535 & 42.7 \\
\hline & $>3$ & 177 & 54.8 \\
\hline \multirow[t]{3}{*}{$10 \mathrm{vr} . \mathrm{M}$} & 0 & 1080 & 22.0 \\
\hline & 13 & 1096 & 34.3 \\
\hline & -3 & 737 & 36.0 \\
\hline \multirow[t]{3}{*}{$10 \vee r . F$} & 0 & 1024 & 31.9 \\
\hline & 113 & 1059 & 44.8 \\
\hline & $>3$ & 719 & 49.7 \\
\hline \multirow[t]{3}{*}{12 vr. 11} & 0 & 486 & 28.4 \\
\hline & $1-3$ & 492 & 31.3 \\
\hline & $>3$ & 335 & 36.4 \\
\hline \multirow[t]{3}{*}{12 yr. F } & 0 & 383 & 29.2 \\
\hline & $1-3$ & 371 & 42.0 \\
\hline & $>3$ & 277 & 53.8 \\
\hline
\end{tabular}

'Years of continuous enrollment in the school dental service.

there text for criteria. 
TABLE IV

GINGIVAL ASSESSMENTS FOR CHILDREN ENROLLED IN THE

SOUTH AUSTRALIAN SCHOOL DENTAL SERVICE IN 1976, AS

RELATED TO EXPOSURE TO SCHOOL DENTAL CARE

\begin{tabular}{lccc}
\hline Age-Sex & $\begin{array}{c}\text { Years Exposed to } \\
\text { School Dental Care }\end{array}$ & $\begin{array}{c}\text { Number of } \\
\text { Subjects\# }\end{array}$ & $\begin{array}{c}\text { Percentage without } \\
\text { Gingivitis }\end{array}$ \\
\hline 6 yr. M & 0 & 726 & 30.3 \\
& $1-3$ & 502 & 31.3 \\
\hline 6 yr. F & $>3$ & 3 & - \\
& 0 & 685 & 31.1 \\
& $1-3$ & 542 & 33.6 \\
\hline 8 yr. M & $>3$ & 4 & - \\
& 0 & 470 & 18.5 \\
& $1-3$ & 635 & 21.1 \\
\hline 8 yr. F & $>3$ & 63 & 23.8 \\
& 0 & 417 & 17.5 \\
& $1-3$ & 602 & 24.9 \\
\hline 10 yr. M & $>3$ & 59 & 22.0 \\
& 0 & 478 & 13.6 \\
& $1-3$ & 432 & 18.5 \\
\hline 10 yr. F & $>3$ & 289 & 20.1 \\
& 0 & 406 & 20.2 \\
& $1-3$ & 414 & 28.0 \\
\hline 12 yr. M & $>3$ & 273 & 15.8 \\
& 0 & 203 & 21.0 \\
\hline 12 yr. F & $1-3$ & 205 & 21.4 \\
& $>3$ & 159 & 15.8 \\
& 0 & 139 & 24.4 \\
\hline Yar. & $1-3$ & 119 & \\
\hline
\end{tabular}

'Years of continuous enrollment in the school dental service.

\#Sample of one in three enrolled children.

tSee text for criteria.

calibration, widely accepted indexes, and control of who was to receive school dental care and when, the study design does not resemble that of an ideal experiment. ${ }^{7}$ While quasi-experimental designs can be encouraged when better approaches are impossible, it is important that uncontrolled variables be considered carefully, and that an appropriate level of skepticism be accorded to findings.

\section{Influence of Extraneous Variables}

Campbell and Stanley have enumerated various classes of extraneous variables which can confound a study's internal validity. ${ }^{5}$ They initially cite history, 
a term to embrace those specific events occurring between the first and second measurement in addition to the test variable. For example, it is entirely possible that in the first phase of this study, there was an improvement in oral hygiene practices as a consequence of social changes occurring in the period between the baseline and follow-up survey. Furthermore, it is possible that history was responsible for the superior assessments for recall patients than for new school dental patients in the follow-up survey in phase one. Perhaps those with a record of dental care in school tended more to come from localities where the positive effects of history on oral hygiene status and gingival health were the most pronounced. However, there are several reasons why confounding effects of history in this study seem unlikely. First, a previous study based on data from a single teaching clinic for therapists, which served a localized area, provided similar results. ${ }^{26}$ Second, essentially the same findings pertained to phase two and three of the present study, even though the Service had grown and the number of clinics and localities in the latter phases was 63, as opposed to 14 in phase one. Accordingly, a continuity of findings is evident for different points in time and for different geographic locations.

Maturation ${ }^{5}$ has been used as a generic term for processes within subjects which operate as a function of the passage of time. Although maturation could have had an effect, as for example during the years of phase one, it is difficult to imagine how collective findings could have been affected seriously in the cross-sectional comparisons used in this study. Had children been followed longitudinally, and comparisons made on a "before-and-after" basis, the natural changes in the children's dentitions might have created problems.

Testing, ${ }^{5}$ the effects of a test (or examination) on the scores of a subsequent test, is not thought to be a source of experimental bias in this study, because the assessments of oral hygiene status and gingivitis were a normal part of every examination in the School Dental Service. In other words, these assessments were not a separate activity introduced periodically for the purposes of evaluation. That is not to say that the examination process would not have influenced the dependent variables; rather, that if it did have an effect, then this would be a normal feature of the program.

It is clear that examiner variability could have introduced appreciable bias, particularly as there was no calibration, staff turnover was high, and conditions were classified so subjectively. For example, this factor may have led to the lower oral hygiene ratings for new school dental patients in the 1972-73 survey, when compared with baseline levels. Calibration of the 174 dentists and therapists would naturally be desirable, but would be virtually impossible to achieve when one considers their geographical distribution, the disruption to normal duties that calibration would cause, and the clinical staff's lack of orientation toward research. However, continuity of results is apparent for different points in time, different indexes, and for different groups of examiners in this and in another study, ${ }^{26}$ which would tend to validate the results found. It is likely that the examinations of treated children were "blind," insofar as the number of cycles or years of past care were concerned; virtually all these children would have obtained a complete cycle of care about nine months previously, and so would not be distinguishable by the extent of accumulated treatment needs. It therefore is encouraging to observe the 
tendency in phase two and in the investigation of the single teaching clinic $^{26}$ for oral hygiene assessments of treated children to improve progressively with the number of cycles or years of care.

Statistical regression toward the mean can be a source of bias, particularly when a comparison group is formed on the basis of extreme index scores. ${ }^{5}$ As none of the comparison groups was formed on this basis in the present study, statistical regression is not regarded seriously as a source of bias. Without randomization, however, it cannot be assumed that any regression toward the mean would have affected all comparison groups equally, and so the potential for bias must be acknowledged. Misleading findings from differential selection ${ }^{5}$ and differential $l o s s^{5}$ of subjects are a possibility, particularly in the absence of randomization. Again, the consistency of findings for the three phases of this study, and for the previously reported study at the teaching clinic, ${ }^{26}$ is reassuring.

The deficiencies in the nonexperimental research design used in this study are evident. Nevertheless, the hypothesis of a positive association between a history of school dental care and better levels of oral hygiene and gingival health has escaped rejection.

\section{Value of Research Design}

With so many sources of potential bias, however, the question of whether studies with this type of design should be undertaken should be considered. It seems inappropriate to condemn them automatically because their design is less than ideal; the alternative frequently is no formalized evaluation at all. The employed design has the advantages of low cost and no disruptions to school routines. Large volumes of data can be produced on a frequent or continuous basis for the evaluation of programs in local areas, and to use in communications with associated parent and teacher groups. The goals of this method of evaluation are quite different from more stringent state-wide surveys that have been conducted periodically. ${ }^{27,25}$

From the evidence presented in this paper, the effects of dental health education on levels of oral hygiene and gingival health cannot be separated from the effects of other aspects of the treatment program. The design of the evaluation study precludes stating conclusively that gingival health and levels of oral hygiene have been improved. Even if they have, true cause-and-effect relations with dental health educational procedures cannot be defined. However, the results at least are encouraging, and give some grounds for considering that desirable habits of oral hygiene develop as a result of the school dental program. But unless more sophisticated approaches to evaluation can be developed, the effects of dental health education in school dental care programs will never be tested separately. Should they be? One must conclude so, and consider it important that school dental care programs continue to develop and refine evaluative models directed at assessing health outcomes.

\section{References}

1. American Dental Association, Board of Trustees. Supervision of dental auxiliaries. Am. Dent. A. Tr., 116:585, Dec. 16, 1975.

2. Applewhite, H. L. Dental health education in the schools. Am. J. Pub. Health, 60:1835-8, Sept. 1970.

3. Barmes, D. E. Features of oral health care across cultures. Internat. Dent. J., 26:353-68, Sept. 1976.

4. Beck, D. J. Dental health status of the New Zealand population in late adolescence ana young 
adulthood. Wellington, N. Z., National Health Statistics Centre Special Report No. 29, Government Printer, 1968. $106 \mathrm{p}$.

5. Camphell, D. T., and Stanley, J. C. Experimental and quasi-experimental designs for research. Chicago, Rand McNally, cl963. ix +84 p.

6. Cohen, Lois K., and Lucye, Helen. A position on school dental health education. J. Sch. Health, 40:361-5, Sept, 1970.

7. Deniston, O. L., and Rosenstock, I. M. The validity of nonexperimental designs for evaluating health services. Health Serv. Rep., 88:153-64, Feb. 1973.

8. Dunning, J. M. Deployment and control of dental auxiliaries in New Zealand and Australia. Am. Dent. A. J., 85:618-26, Sept. 1972.

9. Eiseman, Seymour. The effectiveness of a conceptual approach to dental health instruction in junior high school. J. Sch. Health, 42:466-71, Oct. 1972.

10. Frazier, $P$. Jean. The effectiveness and practicality of current dental health education programs from a public health perspective; a conceptual appraisal. Paper presented at the annual meeting of the American Public Health Association, Miami Beach, Florida, Oct. 20, 1976.

11. Graves, R. C., McNeal, D. R., Haefner, D. P., and Ware, Beverly G. A comparison of the effectiveness of the "Toothkeeper" and a traditional dental health education program. J. Pub. Health Dent., 35:85-90, Spring 1975.

12. Green, Cornelia. A dental health education program for the primary level. Wis. S. Dent. Soc. J, 47:3-10, Jan. 1971.

13. Heifetz, S. B., and Suomi, J. D. The control of dental caries and periodontal disease; a fundamental approach. J. Pub. Health Dent., 33:2-6, Winter 1973.

14. Helm, Sven. National statistics on caries and oral hygiene derived from the Danish Child Dental Health recording system. Community Dent. Oral Epidemiol., 1:121-6, 1973.

15. Holst, Dorthe. Prevalence of gingivitis among children with and without school dental service. Scand. J. Dent. Res., 84:150-7, May 1976.

16. Jordan, W. A., and Pugnier, V. A. Evaluation of dental health education in the Greater Leech Lake dental project of Cass County, Minnesota. J. Pub. Health Dent., 27:21-9, Winter 1967.

17. Kegeles, S. S. Adequate oral health: blocks and means by which they may be overcome. p. 73-122. (In Brown, W. E., ed. Oral Health, dentistry, and the American public. Norman, Okla., University of Oklahoma, c1974. vii $+372 \mathrm{p}$.)

18. Lewis, D. W., GIlbert, S., and Hunt, A. M. Comparison of provincial dental care plans for children in Canada. Toronto, Dental Health Care Services Research Unit, Faculty of Dentistry, University of Toronto, Jan. 30, 1976. n.p., duplicated.

19. Maddick, I. H. Assessment of a programme of dental health education. J. Sch. Health, 40:273-4, May 1970.

20. Maddick, I. H., and Downton, David. Teach yourself dental health. Internat. J. Health Educ., 13:66-71, 1970 .

21. Martens, Leslie V., Frazier, P. Jean, Hirt, Katherine J., Meskin, L. H., and Proshek, J. Developing brushing performance in second graders through behavior modification. Health Serv. Rep., 88:818-23, Nov. 1973.

22. Masters, D. H. The classroom teacher-effective dental health educator. J. Sch. Health, 42:257-61, May 1972.

23. Podshadley, A. G., and Schweikle, Edith S. The effectiveness of two educational programs in changing the performance of oral hygiene by elementary school children. J. Pub. Health Dent., $30: 17-20$, Winter 1970 .

24. Podshadley, A. G., and Shannon, Jean H. Oral hygiene performance of elementary school children following dental health education. J. Dent. Child., 37:298-300, 302, July-Aug. 1970.

25. Rayner, Jeannette F., and Cohen, Lois K. School dental health education. p. 275-307. (In Richards, N. D., and Cohen, Lois K., eds. Social sciences and dentistry: a critical bibliography. The Hague, Sijthoff, cl971. 381 p.)

26. Roder, D. M. The effects of dental care provided at the South Australian School of Dental Therapy. Nat. Hosp. Health Care, 2:23-9, May 1976.

27. The effect of treatment provided by dentists and therapists in the South Australian School Dental Service. Austral. Dent. J., 18:311-9, Oct.-Dec. 1973.

28. The effect of treatment provided by dentists and therapists in the South Australian School Dental Service. The second report. Austral. Dent. J., 21:147-52, Apr. 1976.

29. ㄴ. The school dental therapist of South Australia. J. Pub. Health Dent., 32:70-82, Spring 1972.

30. Roder, D. M., Sundrum, Palam, Boundy, Helen, and Inger, Mary. The effect of a pilot dental health education programme on high school students. Austral. Dent. J., 22:6-10, Feb. 1977.

31. Short, A. G. Dental health education and the school dental nurse, N. Z. Sch. Dent. Gaz., 33:5-7, Feb. 1973. 
32. Smith, L. W. Evans, R. I., Suomi, J. D., and Friedman, L. A. Teachers as models in programs for school dental health; an evaluation of the "Toothkeeper." J. Pub. Health Dent., 35:75-80, Spring 1975.

33. Stacey, D. C., Abbott, D. M., and Jordan, R. D. Improvement in oral hygiene as a function of applied principles of behavioral modification. J. Pub. Health Dent., 32:234-42, Fall 1972.

34. Stamm, J. W., Kuo, H. C., and Neil, D. R. An evaluation of the "Toothkeeper" program in Vermont. J. Pub. Health Dent., 35:81-4, Spring 1975.

35. Todd, J. E. Children's dental health in England and Wales 1973. London, Her Majesty's Stationery Office, 1975. vi $+387 \mathrm{p}$.

36. World Health Organization. Oral health surveys; basic methods. 2nd ed. Geneva, The Organization, $1977.68 \mathrm{p}$.

37. Zody, S. L. A study comparing a dental health education program among first, third, and sixth grade children. Ind. S. Dent. A. J., 49:93-8, Mar. 1970.

\section{From President ADA to President USA}

August 3, 1977

The President

The White House

Washington, D. C. 20500

Mr. President:

I am writing on behalf of the 125,000 members of the American Dental Association to express the strong endorsement of the dental profession for statements which you have made regarding the need for emphasis upon prevention in private and public health programs. In addition, I wish to bring to your attention and request your assistance in connection with a matter of special and immediate importance to the dental profession and to the dental health of our citizens.

As you know, the fluoridation of public water supplies at optimal levels is one of the most effective disease prevention measures known to science. More than 30 years of experience has demonstrated that it is safe and economical and can reduce the incidence of dental caries by as much as $65 \%$. The dental profession greatly appreciates your recognition of these facts as evidenced by your staunch support of water fluoridation projects while you were Governor of Georgia. We urge your continued support for fluoridation as a prime preventive measure in those health care programs which you will be proposing.

The immediate problem I would like to bring to your attention arises from a particular aspect of the National Interim Primary Drinking water Regulations that were promulgated by the Environmental Protection Agency on June 24, 1977, pursuant to the Safe Drinking Water Act (P.L. 93-523). These regulations list fluoride as a "Contaminant" if it naturally occurs in a public water supply at more than twice the optimum level and in such cases requires a downward adjustment of the fluoride content.

While the Association is fully supportive of the intent of the regulations which is to assure the purity and safety of all drinking water, we are concerned that by utilizing the terms "contaminant" and "health hazard", a side effect of the regulations will be to greatly hinder community efforts to fluoridate water supplies to the optimal level. This is likely to occur because of the harshness of the terms that are used and their differing connotations for the scientific community and for the general public. 
Also of serious concern is the fact that under the regulations nearly 1,000 communities will be required to undertake the costly procedure of reducing the naturally occurring fluoride level of their water supplies in order to meet the EPA standard, for which no federal assistance is provided under existing law.

In order to deal with these interrelated problems, we would respectfully request your consideration of the following two actions.

First, the dental profession believes it would be most helpful to receive from you a reiteration of support for fluoridation as a safe and effective public health measure, an action which has been taken by a number of your predecessors as President, and

Second, we would request your initiation and support of legislation authorizing federal assistance to communities to meet the initial cost of installing and beginning to operate equipment necessary to adjust the fluoride content to the optimal level. Such legislation has been sponsored by the American Dental Association for several years, and, although it has twice passed the Senate it has not been enacted. I am enclosing a copy of the most recent bill for your consideration.

For your information our Association has already been in contact with Dr. John C. Greene, Chief Dental Officer of the U. S. Public Health Service, Dr. Irving Bellack of the Environmental ProtectionAgency and staff personnel of the Preventive Dentistry Unit of the Center for Disease Control with regard to this issue.

The American Dental Association is extremely pleased, as indicated above, to note your strong emphasis on prevention as a key to better health for all Americans. We are desirous of working with you in obtaining this goal not only in upcoming legislation but with regard to the matters discussed in this letter.

If convenient for your staff, liaison can be established thrugh our Washington ()ffice, 1101 17th Street, N.W., Suite 1004, Washington, D. C., 20036 (202-833-3036). Hal M. Christensen is Director of this Office.

We greatly appreciate your attention to this matter.

Sincerely, $/ \mathrm{s} /$

Frank F. Shuler, D.D.S.

President

American Dental Association

For President Carter's Response, see page 98. 